Check for updates

Bengaluru, India

emailpriyanka@gmail.com

Cite this as: BMJ 2022;376:n3146

http://dx.doi.org/10.1136/bmj.n3146

Published: 07 January 2022

\section{How covid-19 vaccines exposed India's adverse events reporting system}

\begin{abstract}
Adverse events are among the most heavily scrutinised parts of the covid-19 vaccine process. But India's system was woefully unprepared for this, leaving families confused, sowing vaccine hesitancy in communities, while robbing the system of valuable data, reports Priyanka Pulla
\end{abstract}

\section{Priyanka Pulla freelance journalist}

Around a week after she received her first dose of Covishield, the Indian version of AstraZeneca's covid-19 vaccine, 20 year old Rijuta developed a blinding headache. On 2 June 2021, she was admitted to a large corporate hospital in Bhopal city, Madhya Pradesh. Imaging and blood tests revealed a clot in her brain, says her friend Ajay, while her platelet counts dropped precipitously.

Concerned, the family approached a reputable neurosurgeon for a second opinion. The

neurosurgeon told the family that Rijuta's symptoms were consistent with thrombosis with thrombocytopenia syndrome (TTS), the very rare adverse event that occurs between 0.5 and 6.8 times for every 100 ooo jabs. "But she said that no one could confirm it," Ajay told TheBMJ. When the family raised the possibility of Rijuta's illness being linked to the vaccine with the doctors treating her, they dismissed the idea. Rijuta, who was studying for her bachelor's degree in arts, died on 20 June.

Despite the strong evidence that existed by then that TTS could be caused by the AstraZeneca vaccine, ${ }^{2}$ the Bhopal hospital didn't report Rijuta's case to India's covid-19 vaccine safety surveillance system. Ajay says Rijuta's family couldn't do so either because they didn't know how to report it.

Rijuta's case highlights just two of the many gaps that plague India's covid-19 vaccine safety system: hospitals are failing to report adverse events following immunisation (AEFI), while patients and their families don't know how to do it. But the system is also constrained by other problems, including the slow pace at which officials are investigating whether reported adverse events are due to vaccines and the non-communication of their findings with patients.

This has left not only an incomplete picture of vaccine safety in India but also confusion among the families of the victims of serious AEFIs that result in death or prolonged hospitalisation.

Such a situation is likely to trigger vaccine hesitancy, says Gagandeep Kang, a public health microbiologist at the Christian Medical College, Vellore, who helped develop India's first rotavirus vaccine. "For families to not even have acknowledgment of the reason they lost a child is callous," she said.

\section{Multitude of challenges}

Among the hurdles facing the covid vaccine safety system is the difficulty in adapting India's existing paediatric immunisation programme to adults. Before
January 2021, the Indian government's immunisation programme was aimed at children. So, when the country began vaccinating healthcare workers that month, the post-licensure safety surveillance system for children's vaccines had to be modified for adult vaccines.

This system is three tiered. Once a hospital or healthcare provider voluntarily reports a serious AEFI, a district committee gathers all related data and sends them to a state committee. The state committee then investigates whether the AEFI is causally related to the vaccine, and sends the data to a national committee for verification. After verification, these data are supposed to go back to immunisers and vaccine recipients. This feedback loop is critical because it helps immunisers avoid errors and handle AEFIs better, while also bringing closure to victims of serious adverse events.

However, before the pandemic most of the experts sitting on state and national committees were paediatricians. When covid-19 vaccines were developed, the committees had to hurriedly recruit adult physicians, such as cardiologists and neurologists, and train them in causality assessments.

Furthermore, adult physicians have not been used to reporting vaccine adverse events. "Many of them may never have heard of AEFIs, they may not know where to report them," said Jyoti Joshi Jain, who Technical Support Unit, which advises the Indian health ministry on its immunisation programmes.

Even though the central government sent letters asking district officials to sensitise hospitals about reporting, "relatively fewer reports" are coming from India's large private healthcare sector, said Satinder Aneja, who leads the national committee which investigates vaccine AEFIs. This data gap is significant, because over half of all Indians approach the private sector for treatment when they become ill. ${ }^{3}$

On top of this, the pandemic and the immunisation programme itself have stretched the safety system. The members of the national committee, for instance, not only continue to evaluate AEFIs arising from childhood immunisation but are also involved in covid policy making. Meanwhile, district immunisation officers have to meet high vaccination targets, while also pushing hospitals to report adverse events and collecting the necessary medical records to investigate them. previously worked with New Delhi's Immunisation 
The net result is very low levels of reporting, delay in the collection of medical records, and slow causality assessments. As of 30 November 2021, the national committee had received 49819 adverse events reports, according to a response filed by India's health ministry in the country's parliamentary upper house. ${ }^{4}$ By then, India had administered 1.23 billion vaccine doses, which means that Indian healthcare providers had reported only about four adverse events for every 100 ooo doses. In contrast, the Canadian safety surveillance system received 48 reports for 100 ooo doses until 3 December 2021, ${ }^{5}$ while the UK had received 300-700 per 100 ooo doses up to 16 December $2021 .^{6}$

Reporting rates for TTS are similarly low, with only 26 reports having reached the national committee so far. And the reports that do reach the national committee are investigated slowly. Of the 946 deaths reported up to November 2021, the committee had completed investigations for only 89 . And of the 26 TTS cases by mid-December 2021, only six have been investigated at the time of writing, with five attributed to Covishield.

Aneja said the speed of investigation was hampered by how long it was taking states to send medical records and postmortem reports. Distinguishing between causally related and coincidental adverse events often requires sophisticated medical investigations, which aren't always done by hospitals, especially in the chaos of the pandemic. "The safety system relies on the healthcare system, and the healthcare system itself has been overburdened and overwhelmed in the last two years," she said.

\section{Fixing the system}

Many of the problems with India's covid vaccine safety system were presaged by its paediatric vaccine safety system. In a 2017 paper, Jain and her colleagues described how the system had grown rapidly, ${ }^{7}$ but still suffered from considerable under-reporting. Against a global benchmark of at least 10 AEFI reports for every 100 ooo live births, the country was then reporting only 4.2 AEFIs.

Asked how the system could be strengthened, a senior official, who requested not to be named, said there was an urgent need to facilitate self-reporting by patients and their families. A government body known as the Indian Pharmacopoeia Commission does allow patients to report drug and vaccine adverse reactions, but poor awareness of this service means that it hasn't contributed much to AEFI reports. As of mid-December 2021, the commission had received only around 225 of the 49819 reports, the official told The BMJ.

Another key intervention would be an active surveillance programme to identify rare events such as TTS and multisystem inflammatory syndrome. Compared with the current passive system, in which doctors can choose whether to report an adverse event, an active one would solicit such information from healthcare providers. Aneja says the Indian government has had plans to roll out an active surveillance system since 2020, but the exercise was taking time, given how resource intensive it was. She added that a self-reporting system was also expected to be up and running next year.

Aneja says that it is also necessary to supplement the national and state committees. Since India began its covid immunisation programme, the government has appointed a 30 member sub-committee dedicated to covid vaccine causality analysis, which supports the 27 member national committee. Even so, Aneja says, these committees cannot handle the large load of verifying causality assessments from across India in a short time. "We may need to decentralise and put in place 3-4 regional committees.”
The need for these interventions couldn't be more urgent. With only half of India's adults fully immunised, and the threat of omicron looming large, improving vaccination rates is crucial. And a few surveys ${ }^{8}$ show that hesitancy could be a significant barrier to this goal.

A strong safety system will also allow finer calculations of a vaccine's benefit-risk ratio in specific age groups. For instance, on the basis of data showing that younger people had a higher risk of TTS and a lower risk of severe covid-19, the UK is now offering alternatives to AstraZeneca's vaccine among healthy adults under 40. ${ }^{9}$ In December 2021 India opened up vaccinations to 15-17 year olds, among whom severe covid-19 is even rarer, making a sensitive safety surveillance system critical. ${ }^{10}$

Such a system will also prevent needless deaths due to vaccines, as in the case of TTS, where the right treatment can cut mortality. "We need to know that TTS is being recognised, because we know that recognising it allows for appropriate early treatment," Kang says. With India's slow rate of investigation into TTS, this information currently doesn't exist.

\section{Families left in the dark}

In July 2021, Tamil Nadu based entrepreneur Venugopalan Govindan lost his 20 year old daughter, Karunya, after she became ill following her first Covishield jab. Karunya, who was studying for a masters degree in data science, was diagnosed with multisystem inflammatory syndrome, a condition that appears on the World Health Organization's list of adverse events of special interest for covid vaccines. ${ }^{11}$ These events are so called because there is a theoretical possibility that they may occur after covid vaccination, although no evidence exists yet. For this reason, WHO advises that such events be monitored carefully.

When Karunya was admitted to hospital, Govindan suspected a link with the vaccine, but did not know where to report it. In desperation, he contacted the Serum Institute of India, the manufacturer of Covishield. The institute says it reported this information to a pharmacovigilance programme for manufacturers, which is supposed to forward the information to the covid vaccine safety system.

Aneja said that government policy was to communicate the results of causality analysis for all serious adverse events to recipients. Yet several state officials told The BMJ they were not aware of any such policy. "We only communicate the results to the district committee. There is no policy to tell patients," Vinay Kumar, state immunisation officer for Tamil Nadu said. In any case, Govindan says he didn't receive any updates on the information he submitted to the Serum Institute of India.

Frustrated, he has taken to social media to publicise his daughter's story. His appeals were then heard by a senior official associated with the safety system, who collected Karunya's medical records again. Eventually, on 29 October 2021, the official informed Govindan that the committee had classified the link between his daughter's death and the vaccine as "indeterminate"-a term used when an adverse event occurs soon after vaccination, but there isn't enough evidence to arrive at a causal link.

For other families, who didn't go public with their stories, getting the results of causality analyses has proved harder, if not impossible. Govindan says several families have found it difficult to persuade doctors to report deaths in the first place. "No one knows that a reporting system exists. Even when someone knows, they have to be extremely persistent to get deaths registered." Once reported, the system is "a black hole," he adds, with no assurance that a case 
will be dealt with in a time bound manner. Also, India doesn't currently have any countrywide compensation programme for vaccine related injury.

For Govindan, the entire situation is especially grating because Indian government officials have frequently miscommunicated the risk from covid vaccines in the last year. In their eagerness to promote vaccination, government officials often claimed that covid vaccines were completely safe, ${ }^{12}$ even though this statement isn't true of any vaccine. Further, recipients were rarely counselled during their appointments about the small possibility of serious adverse events.

The entire experience has left Govindan and many of his family unwilling to take their second doses of vaccine. "Myself and my wife, who are single jabbed, are totally staying away from that poison. And so also my brother and his wife," he says.

Competing interests: I have read and understood the BMJ policy on declaration of interests and declare the following interests: Reporting for this story was supported by a grant from the Thakur Family Foundation. The foundation exerts no editorial influence on the work.

Commissioning and peer review: Commissioned; not externally peer reviewed.

1 World Health Organization. Guidance for clinical case management of thrombosis with thrombocytopenia syndrome (TTS) following vaccination to prevent coronavirus disease (COVID-19). 19Jul 2021. https://apps.who.int/iris/bitstream/handle/10665/342999/WHO-2019nCoV-TTS-2021.1-eng.pdf.

2 Wise J. Covid-19: Rare immune response may cause clots after AstraZeneca vaccine, say researchers. BMJ 2021;373:n954. doi: 10.1136/bmj.n954 pmid: 33846162

3 National Family Health Survey (NFHS-4) 2015-16. International Institute for Population Sciences. Dec 2017. http://rchiips.org/nfhs/NFHS-4Reports/India.pdf.

4 Ministry of Health \& Family Welfare. Answer to Rajya Sabha unstarred question 1068. 7 Dec 2021. https://pqars.nic.in/annex/255/AU1068.pdf.

5 Government of Canada. COVID-19 vaccine safety: Weekly report on side effects following immunization. Dec 2021.https://health-infobase.canada.ca/covid-19/vaccine-safety/archive/2021$12-10 \%$

6 GOV.UK. Coronavirus vaccine-weekly summary of yellow card reporting. 24 Dec 2021. https://www.gov.uk/government/publications/coronavirus-covid-19-vaccine-adverse-reactions/coronavirus-vaccine-summary-of-yellow-card-reporting.

7 Joshi J, Das MK, Polpakara D, Aneja S, Agarwal M, Arora NK. Vaccine safety and surveillance for adverse events following immunization (AEFI) in India. Indian J Pediatr 2018;85:139-48. . doi: 10.1007/s12098-017-2532-9 pmid: 29170922

8 Sarkar MA, Ozair A, Sing KK, Subash NR, Bardhan M, Khulbe Y. SARS-CoV-2 vaccination in India: Considerations of hesitancy and bioethics in global health. Ann Glob Health 2021;87:124doi: 10.5334/aogh.3530.

9 GOV.UK. JCVI advises on covid-19 vaccine for people aged under 40. https://www.gov.uk/government/news/jcvi-advises-on-covid-19-vaccine-for-people-aged-under-40.

10 Hindu Bureau. 15-17 age group to get Covaxin from January 3. The Hindu2021 Dec 27. https://www.thehindu.com/news/national/covaxin-only-vaccine-option-for-children-in-15-18years-age-group-says-government/article38049387.ece.

11 World Health Organization. Covid-19 vaccines: Safety surveillance manual. Monitoring and responding to adverse events of special interest (AESIS). 2020. https://www.who.int/docs/defaultsource/covid-19-vaccines-safety-surveillance-manual/covid19vaccines_manual_aesi.pdf.

12 Pulla P. How Covaxin became a victim of vaccine triumphalism. Livemint 2021 May 27. https://www.livemint.com/science/news/how-covaxin-became-a-victim-of-vaccine-triumphalism11622022760541.html.

This article is made freely available for personal use in accordance with BMJ's website terms and conditions for the duration of the covid-19 pandemic or until otherwise determined by BMJ. You may download and print the article for any lawful, non-commercial purpose (including text and data mining) provided that all copyright notices and trade marks are retained. 